\title{
Impacts of Covid-19 and Payment for Forest Environmental Services on Rural Women in Moc Chau district, Son La province
}

\author{
Pham Thu Thuy, Tran Ngoc My Hoa and Hoang Tuan Long
}

\section{Key messages}

- The Covid-19 pandemic has had significant impacts on ethnic minority women in Moc Chau district, Son La province. These impacts include reduced incomes, increased family pressures and workloads, limited access to natural resources for agriculture production activities and impacts on mental health.

- $\quad$ PFES is currently being paid to communities, social organizations, households and groups of households. Women benefit from and have access to earnings from PFES payments to communities, groups of households, and households. The impact of PFES and its ability to support women in the context of Covid-19 depends on amounts paid, when they are paid, and the benefit-sharing mechanisms involved.

- Women participating in focus group discussions highlighted problems they face when implementing PFES, including limited earnings from PFES, lower PFES payments due to increased law enforcement, risks associated with accessing and securing forest use rights, and limited access to information and understanding of policies.

- More researches are needed to assess the long-term impacts of Covid-19 and the role of PFES in helping women cope with the pandemic.

\section{Introduction}

Payment for Forest Environmental Services (PFES) was piloted in Vietnam in 2008 and implemented nationwide from 2011 under Decree No. 99/2010/ND-CP (Trieu et al. 2020). According to Article 61 of the 2017 Law on Forestry, types of forest environmental services provided under PFES in Vietnam include: (1) Soil protection, restriction of erosion and sedimentation of reservoirs, rivers and streams; (2) Regulation and maintenance of water sources for production and social life; (3) Forest carbon sequestration and retention, reduction of greenhouse gas emissions by measures of preventing forest degeneration and forest area decrease and developing forests in a sustainable manner; (4) Protection of natural landscape and conservation of biodiversity of eco-systems for tourism services; (5) Provision of spawning grounds, sources of feed and natural seeds, use of water from forests for aquaculture. Users of regulated forest environmental services such as hydropower plants, clean water supplies, industrial production, tourism businesses, aquaculture, etc. have to pay fees to service providers. PFES has become an important source of finance for the forestry sector, reducing the economic burden on the state budget, increasing revenues for forest owners, and improving the quality and effectiveness of forest protection (Pham et al. 2018).

The Covid-19 pandemic, which has spread across the globe since the beginning of 2020, has seriously affected economies, supply chains, and the lives of people around the world. Many studies have expressed concern about the risk that the pandemic could lead to increased deforestation and loss of biodiversity (FAO 2021) because as household incomes decrease and food becomes less affordable, people in rural areas may shift to harvesting plants and wildlife for food, converting forests to agriculture, and conducting illegal activities that exacerbate deforestation and forest degradation (FAO 2021). In many countries, the pandemic has greater negative impacts on women, as they face greater workloads with children studying from home, caring for their families and facing increasing rates of domestic violence and abuse (RECOFTC 2020).

Previous studies on PFES in Vietnam by Pham et al. (2020) indicate that in times of crisis, PFES plays an important role in supporting rural incomes for daily needs. So, in the 
current context, what impacts has Covid-19 had on rural communities and on women? Based on a case study in Moc Chau district, Son La province, this policy brief analyses PFES benefit-sharing mechanisms, discusses women's access to PFES benefits, and the impacts of PFES benefit-sharing on women during the Covid-19 pandemic. Results of the study in Moc Chau are based on focus group discussions (FGDs) with 166 people (44\% male and 56\% female) and in-depth household interviews with 89 people (46\% male and $54 \%$ female) in five villages.

\section{Impacts of Covid-19 on women in Moc Chau district}

The results of household interviews and FGDs indicate four main impacts of Covid-19 on women in the five villages in Moc Chau district.

Reduced income: During household surveys, $87.5 \%$ of women and $24.4 \%$ of men participating in interviews said Covid-19 has reduced women's income. Members of households in the study villages were traditionally dependent on agriculture production and trade, factory work, work in big cities, or trading tourist goods for their earnings. However, the Covid-19 pandemic has had significant adverse impacts on incomes from these sources. One woman participating in the FGD said, "Because vegetables are mainly sold to tourists, they can't be sold if visitors don't come here. Few wholesalers in Hai Duong came here to buy vegetables, but they could not go due to Covid". Women participating in all FGDs also said commodity prices had fallen significantly, with one saying, "Rice has no price, and zucchini and fruit prices are now 30-40\% lower than before". A female respondent in Lun village added, "In 2019, one kilogram of passion fruit would sell for USD 1.75, but in 2020 it was only worth USD 0.22 Before Covid we could sell large quantities of oranges for USD 1.1 per kilogram, but now we can only sell small quantities at USD 0.44 per kilogram".

Increased pressure and family workload: In household surveys, $35.42 \%$ of women and $26.8 \%$ of men said Covid-19 has put a lot of pressure on women and increased their workload. The pandemic has resulted in some children dropping out of school and women either having to stay at home to look after them or take them to work. As a result, productivity in villages has fallen sharply, especially among women. Many women participating in the FGD in An Thai village reported $40 \%$ lower earnings compared to pre-Covid-19 levels. In Lun village, women are under greater pressure caring for their families with, "farming, food, children studying", while according to women in Phach village, "Men in the village don't care about managing expenditure. It's more difficult for women because they have to do everything themselves".

\section{Limited access to natural resources for carrying out} agricultural productivities: Due to limited land availability and most land being privately owned, many households have to rent land for farming. Many women participating in FGDs in all villages said earnings had fallen while expenses had remained the same, and this had caused many households to return the land they had leased and not being able to afford it for production for at least three or four years.

Impacts on mental health: Household surveys in Lun, Phach and An Thai villages showed $41.67 \%$ of women and $31.7 \%$ of men saying Covid-19 had impacted their mental health with pressure and anxiety over illness, and that increased family work had created great mental pressure for many women. Over $60 \%$ of women and $41.46 \%$ of men interviewed said Covid-19 has had a major impact on children, with travel restrictions and having to study online from home. This has not only affected young children's learning and morale, but also meant women having to stay at home to take care of them or carry them to work in the fields.

Covid-19 has limited social interaction for ethnic minority women, as their outside communication was mainly through social and cultural activities in villages or interaction with relatives living in Laos. The pandemic has created psychological gaps and limited social communication for many women in the study sites. In addition, women participating in FGDs in two of the five villages said increased domestic violence during the Covid-19 pandemic has put a lot of pressure on women.

\section{PFES benefit-sharing mechanisms and impacts on men and women during Covid-19}

Figure 1 below shows PFES financial flows and benefitsharing mechanisms in the study areas.

Table 1 shows payments to forest owners in study sites from 2019 to 2020.

Women have different access to and benefits from each of these benefit-sharing mechanisms. 


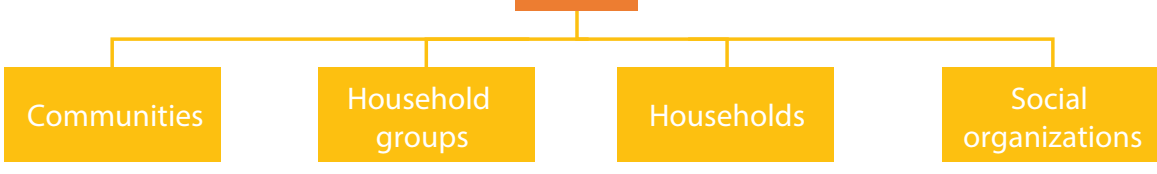

Figure 1. PFES financial flows

Table 1. PFES amounts in study villages, 2019-2020

\begin{tabular}{|c|c|c|c|c|c|c|c|c|c|c|}
\hline \multirow[t]{2}{*}{ Village } & \multirow[t]{2}{*}{ Year } & \multirow[t]{2}{*}{ Total (USD) } & \multicolumn{2}{|c|}{ Households } & \multicolumn{2}{|c|}{ Communities } & \multicolumn{2}{|c|}{ Social organizations } & \multicolumn{2}{|c|}{ Household groups } \\
\hline & & & USD & $\%$ & USD & $\%$ & USD & $\%$ & USD & $\%$ \\
\hline \multirow[t]{2}{*}{ Phach } & 2019 & 11,927 & 7,162 & 60.04 & 496 & 4.16 & 4,269 & 35.79 & 0 & 0 \\
\hline & 2020 & 10,468 & 6,305 & 60.23 & 425 & 4.06 & 3,738 & 35.71 & 0 & 0 \\
\hline \multirow[t]{2}{*}{ Ang } & 2019 & 10,866 & 3,172 & 29.19 & 1,768 & 16.2 & 0 & 0 & 5,926 & 54.54 \\
\hline & 2020 & 9,828 & 2,780 & 28.29 & 1,608 & 16.3 & 0 & 0 & 5,440 & 55.35 \\
\hline \multirow[t]{2}{*}{ Bua } & 2019 & 2,521 & 1,889 & 74.95 & 631 & 25.0 & 0 & 0 & 0 & 0 \\
\hline & 2020 & 2,326 & 1,734 & 74.55 & 592 & 25.4 & 0 & 0 & 0 & 0 \\
\hline \multirow[t]{2}{*}{ Lun } & 2019 & 21,067 & 2,469 & 11.72 & 15,623 & 74.1 & 2,583 & 12.26 & 392 & 1.86 \\
\hline & 2020 & 19,666 & 2,159 & 10.98 & 13,798 & 70.1 & 3,331 & 16.94 & 378 & 1.92 \\
\hline \multirow[t]{2}{*}{ An Thai } & 2019 & 117 & 83 & 71.23 & 34 & 28.7 & 0 & 0 & 0 & 0 \\
\hline & 2020 & 90 & 63 & 70.11 & 27 & 29.9 & 0 & 0 & 0 & 0 \\
\hline
\end{tabular}

Source: Authors' own analysis (2021)

\section{Benefit-sharing for communities}

Table 1 shows all five study villages receiving community PFES payments. FGD results show PFES payments to communities being used for a variety of purposes (Table 2). Villagers in general and women in particular benefit differently from PFES depending on the payment amounts received, and how they are utilized. Of the five study villages, only Lun received significant amount in community PFES payments, with other villages receiving only small amounts.

Approximately $60 \%$ of the money villages received from community PFES payments is used to repair and build new village infrastructure, with around 20\% on average for forest protection and $10 \%$ for other activities. The use of PFES payments has not differed between pre and post Covid-19. As these uses of PFES payments are aimed at distributing benefits equally between households, FGD participants were generally appreciative of their impacts. However, PFES impacts are highly dependent on amounts paid, and as only Lun village received significant payments of about USD 20,000 annually, people in the village were more appreciative of the essential role PFES plays than those in other villages.

Many interviewees in household surveys said community PFES payments do not play an important role in supporting individual villagers in general and women in particular during the difficult situation caused by Covid-19, as they are mainly used for village activities. Only women participating in the FGD in Lun village noted the role of community PFES payments in helping them cope with Covid-19, as such payments had benefited all participating households. With support from the Vietnam Forests and Deltas Program (VFD) and the Son La Forest Protection and Development Fund, the Village Management Board in Lun had held a meeting with villagers and reached an agreement whereby $30 \%$ of the amounts the Son La Forest Protection and Development Fund pays to the community would be used to set up a credit union for economic development. So far, more than 20 households with female 
Table 2. Use of community PFES payments according to FGD participants

\begin{tabular}{|c|c|c|}
\hline How community PFES payments are used & Men answering & Women answering \\
\hline 1. For visiting and taking care of sick people in the village & Ang, Lun, Bua & Ang, Lun \\
\hline 2. For repairing roads and bridges in the village & Ang, Phach & Lun \\
\hline 3. Paying for village meeting expenses & Bua, Phach, An Thai & Bua, Phach, An Thai \\
\hline $\begin{array}{l}\text { 4. Building village infrastructure (schools, cultural houses, canals and } \\
\text { roads) }\end{array}$ & Lun, Phach & Lun, Phach \\
\hline 5. For preventing and fighting forest fires & Lun, Phach & Lun, Phach \\
\hline $\begin{array}{l}\text { 6. After allocation for forest protection, remaining PFES amounts are } \\
\text { used for contributing to village funds }\end{array}$ & Lun & Lun \\
\hline 7. For the Study Promotion Fund & Lun & Lun \\
\hline $\begin{array}{l}\text { 8. For setting up credit unions for women with low interest loans for } \\
\text { members* }\end{array}$ & Lun & Lun \\
\hline
\end{tabular}

Note: * This has only been implemented since 2020

Source: FGD results

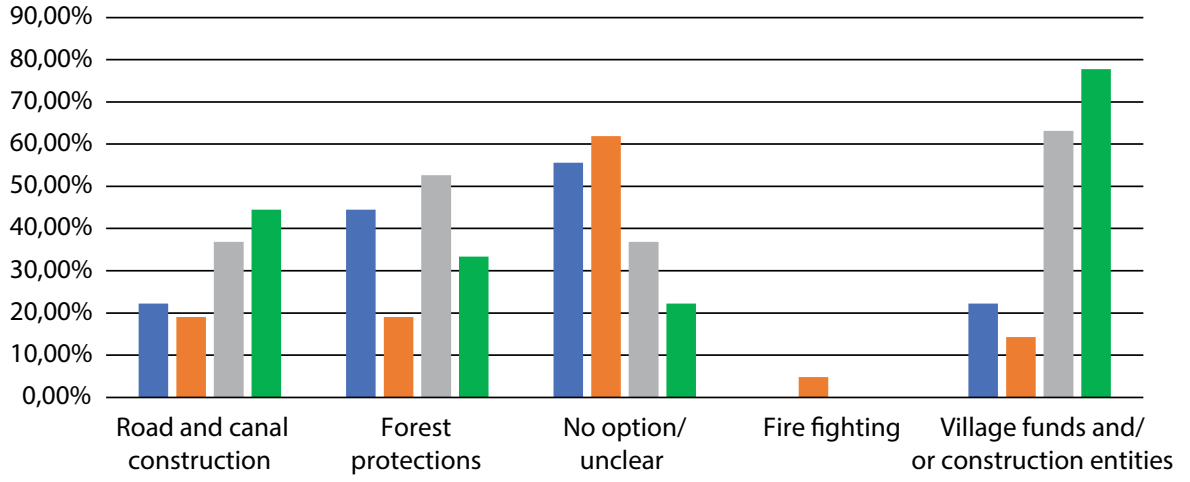

Men - Phach Women - Phach Men - Lun Women - Lun

Figure 2. Shows household interviewees having similar opinions to FGD participants.

Source: Household interviews

members have joined this credit union. In addition to this funding source, each participating female member can buy additional shares at USD 2.19 per share. So far, the total loan amount has reached USD 3,067.06, and the interest earned has helped total available capital reach USD 4,013.46. On average, each participating household will be able to borrow USD 440 at an interest rate of 1\% for 12 months, with the loan capital revolving between members. According to female credit union members participating in the village FGD, this method of benefit-sharing has become very useful and has had a positive impact on women during the Covid-19 pandemic for two reasons. First, with the Covid-19 outbreak, villagers and women in the village have been unable to sell agricultural products and face many difficulties securing capital for growing the next crop. Where women in villages without PFES have many difficulties and are forced to take on high-interest loans, with this low-interest revolving capital, women in Lun village can meet some of the capital needs to finance their livelihoods and can return to production without being burdened by high interest payments. Second, with the mountainous terrain and travel restrictions, many women have been unable to travel to secure statesupported loans with preferential interest rates from farmers' associations, women's unions and banks, and have problems completing the necessary administrative paperwork. Meanwhile, with the village's benefit-sharing model and lending system, they have easy access to loans in a timely manner without having to deal with complicated administrative procedures. 
In addition, FGD and survey results for both men and women also show many challenges in ensuring this mechanism is implemented effectively and fairly. Household survey and FGD results both show that although villages have allocated community PFES funds to pay wages for participating households, only men are allowed to join forest protection groups and benefit from this benefit-sharing mechanism. In Lun village, one male FGD participant said forest fire protection and prevention is more suitable for men, and for each day they participate in forest protection work, they receive USD 6.57. Only around 20\% of women participating in the FGD in Phach village said they had benefited from payments to the community, from their husbands giving them money which is paid from forest protection work, or from being directly involved in forest fire prevention. This suggests women have fewer opportunities than men to benefit from this mechanism.

Another challenge worth noting is that although regulations and guidelines on benefit sharing under the Forest Protection and Development Fund adopted in 2015 (Son La Provincial People's Committee 2015) provide that benefit sharing in villages must be discussed and agreed with all members of the community, Figure 2 shows $62 \%$ of women participating in household surveys in Phach village and 22\% in Lun village saying they were unaware of how PFES money paid to the community was being used. Meanwhile, $55 \%$ of men in these villages were unaware of PFES, and $36 \%$ did not know how the money was used. Many people in Phach and An Thai villages were unaware when PFES started or how money was shared in the village, while people in all three remaining villages knew more about these issues.

\section{Impact of PFES through direct household payments}

According to the provisions of Decree 156, only forest owners with forest use rights certificates whose managed forest area meets PFES payment criteria can receive money from the PFES programme. Households survey and FGD participants had forest use rights for land ranging in area from $200 \mathrm{~m}^{2}$ to $22 \mathrm{ha}$. The average PFES income for households participating in surveys ranged from USD 7 to USD 102 per year, while 5\% of households participating in FGD had incomes of more than USD 440 per year.

The impacts of PFES on households in general and women in particular depend on income levels. For households with small areas of forest, the role of PFES is insignificant, whereas for households with PFES earnings above USD 440 per year, it is a significant source of income. Households
Table 3. Average PFES amount per household (USD)

\begin{tabular}{lcccccc}
\hline & Year & Phach & Ang & Bua & Lun & An Thai \\
\hline \multirow{2}{*}{ Men } & 2019 & 81 & 47 & 21 & 40 & 11 \\
\cline { 2 - 7 } & 2020 & 72 & 102 & 19 & 34 & 9 \\
\hline \multirow{2}{*}{ Women } & 2019 & 76 & 48 & 21 & 37 & 9 \\
\cline { 2 - 7 } & 2020 & 68 & 39 & 19 & 32 & 7 \\
\hline
\end{tabular}

with PFES earnings of more than USD 440 per year can actively use this money to reinvest in production or pay for essential needs such as food and their children's education without getting a loan or having to use their savings. For households receiving PFES earnings of less than USD 44 per year, the impact is not great as they only use the money to buy food.

Both men and women participating in FGDs in Lun and Bua villages said receipt of PFES payments is considered a guarantee for households to borrow money from other households in the village. One resident said, "All households borrow money, but those with PFES will get loans faster and in higher amounts because lenders see PFES as a secure and regular income source".

Although there are different sources of income, FGD and household interview results show similar trends in spending PFES money between villages and between men and women, with all focusing on essential expenditures, such as food, household items, and electricity and water bills (Figure 3).

\section{Payments to household groups}

Table 1 shows that of the five study villages, only Ang and Lun villages have group of household PFES payment. Payments for household groups account for more than 50\% in Ang village, whereas this model accounts for less than $2 \%$ in Lun village. According to statistics, household groups in Ang village receive around USD 370 per year in PFES payments, while in Lun village they receive only USD 161 per year. These groups comprise three to five households living in close proximity to each other, who work together voluntarily to manage and protect forests. According to the results of household interviews and FGDs, as PFES payments are divided equally between households and are quite small, they have little impact on households and women in terms of income. As benefit-sharing mechanisms between groups of households are agreed upon by the households themselves, household interview and FGD participants expressed their satisfaction with this benefit-sharing mechanism. 


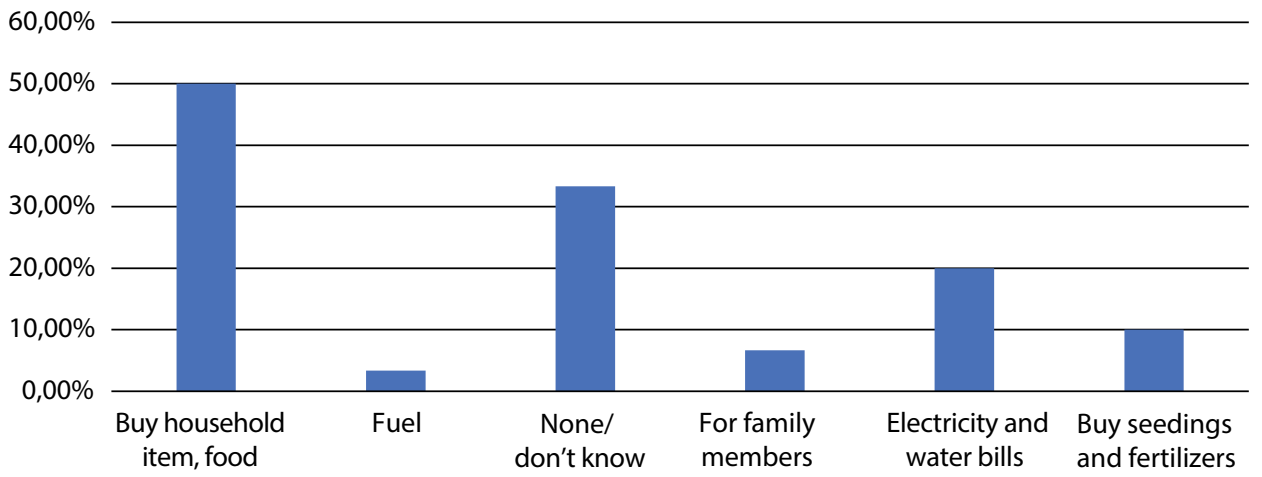

Figure 3. How women household members spend PFES earnings

\section{Payments to social organizations}

Table 1 shows that of the five study villages, only Phach and Lun villages have PFES models that pay social organizations. Though a number of social organizations receive PFES payments (Table 4), the women's union receives the lowest amounts among PFES recipient organizations in Phach village. Meanwhile, in Lun village only the veterans' organization and commune people's committee organize the management and protection of forests and receive payments. Women participating in FGDs said this benefit-sharing mechanism and PFES payments to social organizations do not bring the cash benefits they expect.

\section{Challenges for women in benefiting from PFES}

Women participating in FGDs said they faced many problems in implementing PFES and receiving PFES payments to households.
Amounts received from PFES have decreased due to increased law enforcement: Many women in Ang village said that in the past, state agencies had not carried out regular monitoring and evaluation of forest areas, so people could easily secure PFES payments after showing forest land use rights documentation. However, more rigorous monitoring and verification of forest areas in recent years has shown forest cover falling in many forest areas leading to people receiving less money than they did before Covid19. Some men and women participating in the FGD in Lun village also said because PFES payments had decreased and due to misinformation, some villagers believed that if they fail to protect forest, they might have to go to prison, so they decided not to receive the PFES payments.

Pay rates are low and inconsistent: Both male and female FGD participants said that even though current PFES payments are not commensurate with efforts to protect and develop forests, people do still try to protect them. In addition to being low, earnings from PFES are also inconsistent because they depend on numbers of buyers.

Table 4. PFES amounts received by social organizations (USD)

\begin{tabular}{|c|c|c|c|}
\hline Village & Name of social organization & 2019 & 2020 \\
\hline \multirow{4}{*}{ Phach } & Phach youth union & 1,334 & 1,176 \\
\hline & Phach veterans' organization & 1,602 & 1,402 \\
\hline & Phach farmer association & 1,001 & 869 \\
\hline & Phach women's union & 331 & 290 \\
\hline \multirow{2}{*}{ Lun } & Lun veterans' organization & 2,583 & 2,160 \\
\hline & Commune people's committee & 0 & 1,111 \\
\hline
\end{tabular}


This creates insecurity for rural people, including women. For example, in 2019 some households in Phach village received USD 440 from PFES, but in 2020 only received USD 307.97. As one villager explained, "When people join forest rangers in protecting forest areas they are paid USD 351.97 in the first year, and USD 527.87 in the second year. People in the village have also participated in protecting two hectares of pine forest to safeguard water sources, receiving USD 1,407.87 for the first year, USD 703.83 for the second year and USD 395.9 for the third year. But in the past three years, villagers have not had any more money to protect the forest."

Loss of forest use rights documentation: According to many interviewees, another notable problem is losing forest use rights papers. As one villager explained, "A while ago, commune credit fund officials told people to give them our forest use rights certificates to get government support on forest protection program. However, they have never returned to us since then". Although most villagers do not have the forest use right certificates, they still receive PFES payment and other government programs, so they do not consider the issue to be a problem. However, government officers interviewed shared that without legal document in hand, the participation of these villagers in future forest protection scheme might not be sustainable. Moreover, as villagers do not have hard copy of their forest use right certificate, they cannot neither take loans from the bank nor apply for government microcredit programs.

\section{Limited access to information and understanding of policies: In Phach village, although people have been} issued use right certificate for forest areas to manage, they do not know the precise locations of these areas. Villagers questioned why PFES amounts have decreased over the years but did not know who to ask because payments are sent by post. As many villagers did not attend meetings organized by the village or the government, they knew little about PFES or other state programmes.

Lower PFES payments during Covid-19: Many women participating in the FGD in Lun village said village regulations required the village to deduct $30 \%$ of PFES payments to the community for transfer to a revolving savings fund for women. But due to the Covid-19 situation, the village head had persuaded the women to receive less than the prescribed amount so money could be used for infrastructure repairs and supporting other villagers during the pandemic.

\section{Conclusion}

This infobrief shows that Covid-19 has had a major impact on women in the study area, especially on their earnings, access to land and social networks, and mental health. Study results also show PFES having positive impacts in some study areas through a benefit-sharing mechanism that helps women's groups create small-scale credit unions with revolving loans for group members, and helps women pay for daily necessities and reinvest in production without having to resort to high interest loans. However, the impact and role of PFES in supporting women during the Covid-19 pandemic depends on PFES amounts paid and the area of forest they are entitled to manage. Major challenges for women in benefiting from PFES during the additional burdens caused by Covid-19 are limited and inconsistent payments, and difficulties securing access to resources, forest tenure, and policy information. To guarantee women's rights to access and benefit from PFES, it is necessary to ensure they have access to natural resources, while benefit-sharing mechanisms need to consider needs and aspirations and remove the barriers and difficulties preventing women from accessing and benefiting from PFES. As the full impacts of Covid-19 and PFES on people's lives, and the area and quality of forest cannot be assessed or recognized in a short period of time, more studies are needed to assess the short- and long-term impacts of Covid-19 and the role of PFES in supporting people during this difficult period.

\section{Acknowledgements}

We would like to thank IFPRI and the CGIAR GENDER Platform and COVID-19 Hub for funding this study. We would also like to thank the Son La Forest Protection and Development Fund and Vietnam National Forestry University for their support in conducting this research.

\section{References}

[FAO] Food and Agriculture Organization of the United Nations. 2021. Question and Answer: The impacts of COVID-19 on the forest sector - how to respond? Accessed 15 October 2021. https://www.fao.org/2019ncov/q-and-a/impacts-on-the-forest-sector/en/ Pham TT, Bui Thi MN, Dao Thi LC, Hoang TL, Pham HL and Nguyen VD. 2018. The role of payment for forest environmental services in financial support for the forestry sector in Vietnam. Infobrief 228. Bogor, Indonesia: CIFOR. 
Pham TT, Dao TLC, Nguyen TL, Hoang TL, Nguyen DT and Pham HL. 2020. Economic and social impacts of payments for forest environmental services in Cat Tien National Park. Occasional Paper 215. Bogor, Indonesia: CIFOR.

RECOFTC. 2020. New research shows community forests help people cope with COVID-19. Accessed 15 October 2021. https://www.recoftc.org/news/new-research-showscommunity-forests-help-people-cope-covid-19

Son La Provincial People's Committee. 2015. Decision 1853/

QD-UBND. Law Library. https://thuvienphapluat.vn/van-
ban/Tai-chinh-nha-nuoc/Quyet-dinh-1853-QD-UBND-coche-quan-ly-su-dung-tien-chi-tra-dich-vu-moi-truongrung-Son-La-289670.aspx

Trieu VH, Pham TT and Dao TLC. 2020. Vietnam Forestry Development Strategy: Implementation Results for 20062020 and recommendations for the 2021-2030 strategy. Occasional Paper 209. Bogor, Indonesia: CIFOR.

Vietnam National Assembly. 2017. Law on Forestry: Article 61. Law Library. https://thuvienphapluat.vn/van-ban/Linhvuc-khac/Luat-lam-nghiep-367277.aspx
GENDER This work has been carried out under the CGIAR GENDER Platform, which is grateful for the support of Platform CGIARTrust Fund Contributors. www.cgiar.org/funders

\begin{tabular}{|l|l|l|l} 
This research was carried out by CIFOR as part of the CGIAR Research Program on Forests, Trees and \\
Agroforestry (FTA). FTA is the world's largest research for development program to enhance the role \\
of forests, trees and agroforestry in sustainable development and food security and to address climate \\
change. CIFOR leads FTA in partnership with Bioversity International, CATIE, CIRAD, INBAR, ICRAF and TBI. \\
FTA's work is supported by the CGIAR Trust Fund: cgiar.org/funders/
\end{tabular}

INTERNATIONAL

FOOD POLICY

RESEARCH

IFPRI cifor.org | worldagroforestry.org

\section{CIFOR-ICRAF}

The Center for International Forestry Research (CIFOR) and World Agroforestry (ICRAF) envision a more equitable world where trees in all landscapes, from drylands to the humid tropics, enhance the environment and well-being for all. CIFOR and ICRAF are CGIAR Research Centers.

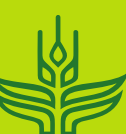

